\title{
Characterization of peptide deformylase homologues from Staphylococcus epidermidis
}

\begin{abstract}
Correspondence
D. Qu

dqu@shmu.edu.cn

X. Shen

xshen@mail.shcnc.ac.cn

H. L. Jiang

hljiang@mail.shcnc.ac.cn
\end{abstract}

Received 13 January 2010

Revised 7 July 2010

Accepted 22 July 2010

\author{
Penghui Lin, ${ }^{1} \dagger$ Tiancen $\mathrm{Hu}^{2}{ }^{2} \dagger$ Jian $\mathrm{Hu},{ }^{1} \dagger$ Wenqi $\mathrm{Yu},{ }^{1} \dagger$ Cong Han, ${ }^{1}$ \\ Jian Zhang, ${ }^{3}$ Guangrong Oin, ${ }^{2}$ Kunqian Yu, ${ }^{2}$ Friedrich Götz, ${ }^{4} \mathrm{Xu} \mathrm{Shen,}{ }^{2}$ \\ Hualiang Jiang ${ }^{2}$ and Di Ou ${ }^{1}$
}
${ }^{1}$ Key Laboratory of Medical Molecular Virology of Ministries of Education and Health, Institute of Medical Microbiology and Institutes of Biomedical Sciences, Shanghai Medical College of Fudan University, Shanghai 200032, China
${ }^{2}$ Drug Discovery and Design Center, State Key Laboratory of Drug Research, Shanghai Institute of Materia Medica, Shanghai Institutes for Biological Sciences, Chinese Academy of Sciences, Shanghai 201203, China

${ }^{3}$ Department of Pathophysiology, Key Laboratory of Cell Differentiation and Apoptosis of Ministry of Education of China, Shanghai Jiao-Tong University School of Medicine, Shanghai 200025, China

${ }^{4}$ Microbial Genetics, University of Tübingen, Auf der Morgenstelle 28, D-72076 Tübingen, Germany

\begin{abstract}
The emergence of multi-drug-resistant strains of Staphylococcus epidermidis emphasizes the need to develop new antibiotics. The unique and essential role of the peptide deformylase (PDF) in catalysing the removal of the N-terminal formyl group from newly synthesized polypeptides in eubacteria makes it an attractive antibacterial drug target. In the present study, both deformylase homologues from S. epidermidis (SePDF-1 and SePDF-2) were cloned and expressed, and their enzymic activities were characterized. $\mathrm{Co}^{2+}$-substituted SePDF-1 exhibited much higher enzymic activity $\left(k_{\text {cat }} / K_{\mathrm{m}} 6.3 \times 10^{4} \mathrm{M}^{-1} \mathrm{~s}^{-1}\right)$ than those of $\mathrm{Ni}^{2+}$ - and $\mathrm{Zn}^{2+}$-substituted SePDF-1, and SePDF-1 showed much weaker binding ability towards $\mathrm{Ni}^{2+}$ than towards $\mathrm{Co}^{2+}$ and $\mathrm{Zn}^{2+}$, which is different from PDF in Staphylococcus aureus (SaPDF), although they share $80 \%$ aminoacid sequence identity. The determined crystal structure of SePDF-1 was similar to that of (SaPDF), except for differences in the metal-binding sites. The other deformylase homologue, SePDF-2, was shown to have no peptide deformylase activity; the function of SePDF-2 needs to be further investigated.
\end{abstract}

\section{INTRODUCTION}

Staphylococcus epidermidis, an opportunistic pathogen, has become one of most prevalent causes of nosocomial infections, especially in patients with prosthetic medical devices such as indwelling catheters or implanted foreign polymer bodies (Rupp \& Archer, 1994; Otto, 2008). S. epidermidis infections on these devices are complicated by the formation of biofilms, which render the bacteria more resistant to multiple antibiotics and host defences (Götz, 2002; von Eiff et al., 2002); replacement of the indwelling medical devices is generally necessary. Therefore, there is an urgent need to develop novel antibiotic agents for the treatment of staphylococcal infections. Peptide deformylase

†These authors contributed equally to this work.

Abbreviations: FDH, formate dehydrogenase; f-MAS, $N$-formyl-Met-AlaSer; PDF, peptide deformylase; RMSD, root-mean-square distance.

Four supplementary figures are available with the online version of this paper.
(PDF, EC 3.5.1.88) is an important enzyme catalysing an essential process in bacterial protein synthesis, and it is considered as a potential antibiotic target for drug design (Sharma et al., 2009). Up to now, there have been no reports about the peptide deformylases from S. epidermidis.

Unlike the synthesis of cytosolic proteins in mammalian cells, protein synthesis in prokaryotes and eukaryotic organelles (such as mitochondria and chloroplasts) starts with an $\mathrm{N}$ formylmethionine, which is formed from methionyl-tRNA by $N$-methionyl-tRNA transformylase. Peptide deformylase catalyses the subsequent removal of the formyl group from the newly synthesized polypeptides (Adams, 1968; Bradshaw et al., 1998; Frottin et al., 2006; Mazel et al., 1994; Meinnel et al., 1993). To date, deformylation has been considered to be unique to prokaryotes (Giglione et al., 2000b; Nguyen et al., 2003; Serero et al., 2003), although some peptide deformylases have been found in organelles of eukaryotes (such as Homo sapiens, Arabidopsis thaliana and Plasmodium falciparum) but with low activities, far lower than that of 
PDFs in prokaryotes (Bracchi-Ricard et al., 2001; Dirk et al., 2001; Lee et al., 2004). Deformylation of nascent peptides is essential for bacterial survival, as it has been shown in Escherichia coli, Streptococcus pneumoniae and Staphylococcus aureus that the def gene cannot be disrupted (Apfel et al., 2001; Margolis et al., 2000; Mazel et al., 1994; Meinnel \& Blanquet, 1994).

PDF enzymes from different species, including E. coli, S. aureus and others, have been cloned and both their threedimensional structures and co-crystal structures with a binding inhibitor have been reported (Baldwin et al., 2002; Cai et al., 2006; Chan et al., 1997; Fieulaine et al., 2005; Guilloteau et al., 2002; Robien et al., 2004; Smith et al., 2003; Zhou et al., 2005; Escobar-Alvarez et al., 2009). Although it has been reported recently that in some species such as Borrelia burgdorferi, Leptospira interrogans and Arabidopsis thaliana, the native PDFs exist as $\mathrm{Zn}^{2+}$-containing forms ( $\mathrm{Li}$ et al., 2002; Nguyen et al., 2007), most native PDF enzymes in bacteria are unique $\mathrm{Fe}^{2+}$-containing metallohydrolases, which are highly active but unstable in vitro due to oxidation (Groche et al., 1998; Ragusa et al., 1998; Rajagopalan et al., 1997). For $\mathrm{Fe}^{2+}$-containing PDFs, by substituting $\mathrm{Fe}^{2+}$ with other divalent transition metals such as $\mathrm{Zn}^{2+}$ (Chan et al., 1997; Meinnel et al., 1995, 1996), $\mathrm{Ni}^{2+}$ (Groche et al., 1998; Ragusa et al., 1998; Wang et al., 2006) or $\mathrm{Co}^{2+}$ (Rajagopalan et al., 2000; Dong \& Liu, 2008), the enzymes retained their activities but were more stable, permitting further biochemical characterization and X-ray crystallographic analysis. Based on sequence homology and crystallographic data, all bacterial PDF enzymes share three highly conserved motifs that are structurally defined as the active sites of these metallohydrolases: motifs 1 GФGФAAФQ, 2 EGCФS and 3 HЕФФН (Meinnel et al., 1997). The catalytic metal ion is tetrahedrally coordinated with the side chains of two histidines from motif 3 , a cysteine from motif 2 and a water molecule hydrogen-bonded to a glutamic acid from motif 3 , the major catalytic site of PDF enzyme (Becker et al., 1998; Rajagopalan et al., 2000).

Based on amino-acid sequences, bacterial PDFs have been grouped into type I, II, and III subfamilies. Type I PDFs exist in bacteria and their homologues have been found in eukaryotes, while type II PDFs are only found in bacteria. Type III PDFs are newly defined in Archaea and trypanosomatids, but have not been thoroughly studied yet. Type II PDF of Gram-positive species differs from type I of Gramnegative bacteria mainly in three major amino-acid insertions (from 3 to 12 amino acids) and a distinct C-terminus (Giglione et al., 2000a; Smith et al., 2003). However, some bacteria, especially Gram-positive bacteria, contain both type I and type II PDF homologes. In the genome of $S$. epidermidis, two PDF homologue genes, def and def-2, were identified. The defgene product, SePDF-1 which shares $80 \%$ amino-acid sequence identity with the functional PDF of S. aureus (SaPDFB, GenBank Accession no. P68826.1) (Baldwin et al., 2002), is classified into the type II PDF subfamily; while the other PDF homologue, SePDF-2, encoded by $d e f-2$, is classified into the type I PDF subfamily.
In the present study, we cloned, expressed, and purified both deformylase homologues from S. epidermidis (SePDF1 and SePDF-2). The characteristics and the crystal structure of SePDF-1 were studied. It was found that SePDF-1 has some different enzymic properties compared with PDF from $S$. aureus, though they share similar protein sequences and structures. The other deformylase homologue, SePDF-2, was shown to have no peptide deformylase activity, and its function needs to be further investigated.

\section{METHODS}

Protein expression and purification. The SePDF-1-encoding gene, def (GenBank Accession no. YP_188262.1), was amplified from the chromosome of S. epidermidis ATCC 35984 (American Type Culture Collection) by PCR with primers 5'-GCGCATCCATATGATAACAATGAAAGATATTATAAGAG-3' (forward) and 5'-CCGCTCGAGGACTTCTACGGCCTCTTCATG-3' (reverse), and then cloned into the prokaryotic expression vector pET-22b $(+)$ (Merck) with NdeI and $\mathrm{XhoI}$ restriction sites to produce the recombinant plasmid pET22b-def with a C-terminal six-histidine tag.

The SePDF-2-encoding gene, def-2 (GenBank Accession no. YP_188364.1), was amplified with primers 5'-GCGGGATCCAAGGAGCCTAAGTGATGACTGT-3' (forward) and 5' - CCGCTCGAGCTCATTGTCAAAATACGCCT-3' (reverse), and then cloned into the prokaryotic expression vector pET-24 (Merck) with BamHI and XhoI restriction sites to produce the recombinant plasmid pET24-def-2 with a C-terminal six-histidine tag.

The recombinant plasmids pET22b-def and pET24-def-2 were transformed into E. coli BL21(DE3) for expression of recombinant proteins. In order to obtain SePDF-1 and SePDF-2 (SePDFs) with unique metal ions, a chemically defined medium was used and the metal ion $\left(\mathrm{Co}^{2+}, \mathrm{Ni}^{2+}\right.$ or $\mathrm{Zn}^{2+}$ ) was added separately. The chemically defined medium contained the following (per litre): $2.5 \mathrm{~g}$ glucose, $10.8 \mathrm{~g} \mathrm{~K}_{2} \mathrm{HPO}_{4}, 5.5 \mathrm{~g} \mathrm{KH}_{2} \mathrm{PO}_{4}$,

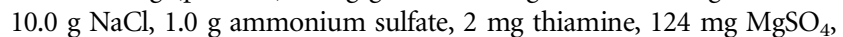
$74 \mu \mathrm{g} \mathrm{CaCl} 2,20 \mu \mathrm{g} \mathrm{MnCl}_{2}, 31 \mu \mathrm{g} \mathrm{H}_{3} \mathrm{BO}_{3}, 1.2 \mu \mathrm{g}\left(\mathrm{NH}_{4}\right)_{6} \mathrm{Mo}_{7} \mathrm{O}_{24}$ and $1.6 \mu \mathrm{g} \mathrm{CuSO}_{4}$ and was fortified with $50 \times$ amino acids solution (SigmaAldrich) (Rajagopalan et al., 2000). E. coli BL21(DE3) containing recombinant plasmids was inoculated into $250 \mathrm{ml}$ chemically defined medium with $100 \mu \mathrm{g}$ ampicillin $\mathrm{ml}^{-1}$ and $100 \mu \mathrm{M} \mathrm{CoCl}_{2}$ (or $\mathrm{NiCl}_{2}$ or $\mathrm{ZnCl}_{2}$ ) and grown at $37{ }^{\circ} \mathrm{C}$ until the $\mathrm{OD}_{600}$ reached 0.6. IPTG (Merck) was added at a final concentration of $0.8 \mathrm{mM}$, and the bacteria were further cultivated at $25{ }^{\circ} \mathrm{C}$ for $12 \mathrm{~h}$. After centrifugation, the pellets were resuspended and sonicated. The recombinant SePDFs were purified by Ni-NTA (Qiagen) affinity chromatography, and all purification procedures were performed at $4{ }^{\circ} \mathrm{C}$.

The purification buffers for SePDFs expressed using $\mathrm{Ni}^{2+}$-fortified medium were compensated with $100 \mu \mathrm{M} \mathrm{NiCl}_{2}$ to avoid possible $\mathrm{Ni}^{2+}$ competition between Ni-NTA and SePDFs. After the purification, the recombinant SePDFs with different metal ions were dialysed against dialysis buffer (buffer D: $20 \mathrm{mM}$ Tris/HCl, pH 8.0, $500 \mathrm{mM}$ $\mathrm{NaCl}$ ) to remove imidazole and free metal ions. The concentration of the purified proteins was determined by Bradford assay.

The metal content of SePDF-1 was determined as p.p.m. by using an AA-220 atomic absorption spectrometer (Varian) with $\mathrm{Co}^{2+}$-specific absorption at $240.7 \mathrm{~nm}, \mathrm{Ni}^{2+}$-specific absorption at $232.0 \mathrm{~nm}$ and $\mathrm{Zn}^{2+}$-specific absorption at $213.9 \mathrm{~nm}$, and then converted to mol $\mathrm{l}^{-1}$. The molar ratios for $\mathrm{Co}^{2+}-, \mathrm{Ni}^{2+}$ - and $\mathrm{Zn}^{2+}$-substituted SePDF-1 were calculated by dividing the metal contents by enzyme concentrations, to indicate the number of metal ions bound per protein. The metal content of SePDF-1 stripped by EDTA was measured as a negative control. 
Oligomeric state analysis. The oligomeric state of SePDF-1 was studied by gel-filtration chromatography using an AKTA purifier system (GE Healthcare). The recombinant Co-SePDF-1 was used in the following experiments. The protein sample was chromatographed on a HiLoad 16/60 Superdex 75 prep-grade column (GE Healthcare) at a flow rate of $1 \mathrm{ml} \mathrm{min}^{-1}$ with buffer D. The Superdex 75 column was calibrated with the following low-molecular-mass standards: conalbumin $(75.0 \mathrm{kDa})$, ovalbumin $(43.0 \mathrm{kDa})$, carbonic anhydrase $(29.0 \mathrm{kDa})$ and RNase A (13.7 kDa) (GE Healthcare).

Enzymic activity assay. The enzymic activities of the recombinant SePDFs with different metal ions were evaluated by the PDF/FDH (formate dehydrogenase, EC 1.2.1.2) coupled assay (Chen et al., 2000; Lazennec \& Meinnel, 1997). During the assay, the formate released by PDF from f-MAS ( $\mathrm{N}$-formyl-Met-Ala-Ser) was oxidized by FDH, thereby reducing one molecule of $\mathrm{NAD}^{+}$to $\mathrm{NADH}$. All assays were carried out in a 96-well plate spectrophotometer at $37{ }^{\circ} \mathrm{C}$ (Beckman Coulter DTX880) by measuring the increase in absorbance at $340 \mathrm{~nm}\left(\varepsilon=6180 \mathrm{M}^{-1}\right.$ $\left.\mathrm{cm}^{-1}\right)$. The conditions, including concentrations of FDH, PDF and the substrates, used in the assays were optimized based on the protocols of Lazennec \& Meinnel (1997) and Chen et al. (2000). The optimized assay solutions (total volume $200 \mu \mathrm{l}$ ) contained $50 \mathrm{mM}$ HEPES, pH 7.5, $10 \mathrm{mM} \mathrm{NaCl}^{0} 0.2 \mathrm{mg} \mathrm{BSA} \mathrm{ml}^{-1}$ (Sangon), $8 \mathrm{mM} \mathrm{NAD}^{+}$(Fluka), $0.5 \mathrm{U}$ $\mathrm{FDH} \mathrm{ml}^{-1}$ (Fluka) and f-MAS (Scipeptide). The reactions were initiated by adding diluted SePDF enzymes to the assay solutions.

SePDF-1 crystallization and data collection. Prior to crystallization, the purified recombinant Co-SePDF-1 was concentrated to $10 \mathrm{mg} \mathrm{ml}^{-1}$. An initial screening was performed at $4{ }^{\circ} \mathrm{C}$ by the hanging-drop vapour-diffusion method using Crystal Screen kits 1 and 2 (Hampton Research). Drops were prepared by mixing $1 \mu \mathrm{l}$ protein solution with $1 \mu \mathrm{l}$ reservoir solution and equilibrated against $500 \mu \mathrm{l}$ reservoir solution, following the procedure described by the manufacturer. The conditions yielding small crystals were further optimized by varying the buffer $\mathrm{pH}$ and precipitant concentration. Diffraction-quality crystals were grown in a reservoir solution containing $0.2 \mathrm{M}$ ammonium acetate, $0.1 \mathrm{M}$ trisodium citrate dihydrate pH 5.6 and $30 \%$ (v/v) PEG 4000.

All diffraction data were collected in-house on a Rigaku rotating-anode $\mathrm{X}$-ray generator operated at $50 \mathrm{kV}$ and $100 \mathrm{~mA} \quad(\lambda=1.5418 \AA)$. Diffraction images were recorded by a Rigaku R-AXIS IV ++ imaging-plate detector with an oscillation step of $1^{\circ}$. The crystal-todetector distance was set to $150 \mathrm{~mm}$. The crystals were soaked briefly in a cryoprotectant made by adding $10 \%$ glycerol to the original reservoir solution and flash-cooled in liquid nitrogen for data collection at $100 \mathrm{~K}$. The data were integrated by MOSFLM (Leslie, 1992) and scaled to $2.3 \AA$ by SCALA (Evans, 1993) in the CCP4 program suite. The $R_{\text {merge }}$ of the highest resolution shell is high (58\%), but considering the acceptable redundancy (4.3) and $I / \sigma$ (2) of that shell, we still processed the diffraction data to $2.3 \AA$ A. Complete statistics of the data are summarized in Table 1 .

Determination of the SePDF-1 structure. Crystals of SePDF-1 belong to space group $\mathrm{C} 222_{1}$ with one monomer in the asymmetrical unit. Molecular replacement was carried out by MOLREP (Vagin \& Teplyakov, 1997) using the structure of SaPDFB (PDB code: 1LQW) (Guilloteau et al., 2002) as the search model. The structure was refined by Refmac (Murshudov et al., 1997) and CNS 1.1 (Brünger et al., 1998) and included simulated annealing, energy minimization and B factor refinement. Manual building of the model was carried out with the program Coot (Emsley \& Cowtan, 2004). After several cycles of model building and refinement, most of the residues, including two C-terminal vector residues and the cobalt ion, were clearly positioned in the $2 F_{\mathrm{o}}-F_{\mathrm{c}}$ map. But three residues from the flexible CD loop (Asn80-Asn82) were disordered in the structure and could not be modelled. Water molecules were added automatically with CNS using $3 \sigma$ peaks in the $F_{\mathrm{o}}-F_{\mathrm{c}}$ map and hydrogen bonding
Table 1. Statistics of diffraction data and model refinement

\begin{tabular}{|ll|}
\hline Diffraction data & \\
\hline Space group & $\mathrm{C} 222_{1}$ \\
Cell length $(\AA)(\mathrm{a}, \mathrm{b}, \mathrm{c})$ & $99.288,121.463,45.781$ \\
Cell angles $\left(^{\circ}\right)(\alpha, \beta, \gamma)$ & $90,90,90$ \\
Resolution range $(\AA)$ & $76.92-2.30(2.42-2.30)$ \\
No. of observed reflections $(I / \sigma>0)$ & $55639(7867)$ \\
No. of unique reflections & $12458(1817)$ \\
Redundancy & $4.5(4.3)$ \\
$I / \sigma$ & $17.8(2.0)$ \\
Completeness $(\%)$ & $98.0(100.0)$ \\
$R_{\text {merge }}(\%)$ & $7.1(58.0)$ \\
Refinement and model & \\
Resolution range $(\AA)$ & $30.00-2.30$ \\
No. of reflections $\left(F_{\mathrm{o}} \geqslant 0 \sigma\left(F_{\mathrm{o}}\right)\right)$ & 12427 \\
Free $R$ set & 625 \\
$R$ factor $(\%)$ & 22.7 \\
Free $R$ factor $(\%)$ & 25.3 \\
No. of residues & 182 \\
No. of protein atoms & 1458 \\
No. of water molecules & 62 \\
No. of cobalt ions & 1 \\
Mean $B$ factor of all atoms $\left(\AA^{2}\right)$ & 47.3 \\
Protein main chain atoms & 46.4 \\
Protein side-chain atoms & 48.6 \\
Water molecules & 47.3 \\
Cobalt ion & 46.5 \\
RMSD bond lengths $(\AA)$ & 0.006 \\
RMSD bond angles $\left({ }^{\circ}\right)$ & 1.3 \\
RMSD dihedral angles $\left({ }^{\circ}\right)$ & 23.6 \\
RMSD improper angles $\left({ }^{\circ}\right)$ & 0.81 \\
Ramachandran plot $(\%)$ & 92.4 \\
Most favoured regions & 7.0 \\
Allowed regions & 0.6 \\
Generously allowed regions & \\
\hline
\end{tabular}

requirements, and problematic waters were manually removed if their definition in the electron density map was poor, or their $B$ factors were too high. The final $R$ factor is $22.7 \%$ (free $R$ factor $25.3 \%$ ) according to CNS, and statistics show that the final model of SePDF-1 is well refined (Table 1).

Site-directed mutagenesis of SePDF-2. Site-directed mutagenesis of SePDF-2 was performed with the QuikChange site-directed mutagenesis kit (Stratagene) using the plasmid pET24-def-2 as template and following the manufacturer's instructions. The mutation sites and the primers for mutagenesis are listed in Table 2. The mutant plasmids were confirmed by DNA sequencing before being transformed into $E$. coli BL21(DE3). The methods for expression and purification of the mutated proteins were the same as that of the wild-type SePDFs.

\section{RESULTS}

\section{The deformylase-encoding genes in $S$. epidermidis}

Based on the genomic sequence of $S$. epidermidis ATCC 35984 (GenBank Accession no. NC_002976.3), two deformylase homologue genes were identified. The first of these, 
Table 2. Primers used in the site-directed mutageneses of SePDF-2

\begin{tabular}{|c|c|c|c|}
\hline Name & Sequences $\left(5^{\prime}-3^{\prime}\right)$ & Mutation site & Function \\
\hline S90C & $\begin{array}{l}\text { F: ctgacttagaaggctgtatcagtttacctc } \\
\text { R: gaggtaaactgatacagccttctaagtcag }\end{array}$ & tca-tgt & $\mathrm{S} \rightarrow \mathrm{C}$ \\
\hline I91L & $\begin{array}{l}\text { F: ctgacttagaaggctcactgagtttacctcatatatatg } \\
\text { R: catatatatgaggtaaactcagtgagccttctaagtcag }\end{array}$ & atc-ctg & $\mathrm{I} \rightarrow \mathrm{L}$ \\
\hline SI-90,91-CL & $\begin{array}{l}\text { F: ctgacttagaaggctgtctgagtttacctcatatatatg } \\
\text { R: catatatatgaggtaaactcagacagccttctaagtcag }\end{array}$ & $\begin{array}{l}\text { tca-tgt } \\
\text { atc-ctg }\end{array}$ & $\mathrm{S} \rightarrow \mathrm{C}$ and $\mathrm{I} \rightarrow \mathrm{L}$ \\
\hline A44G & $\begin{array}{l}\text { F: cattatatcatgaggaaggcgctggaattagtgcacctcaaattg } \\
\text { R: caatttgaggtgcactaattccagcgccttcctcatgatataatg }\end{array}$ & gcc-ggc & $\mathrm{A} \rightarrow \mathrm{G}$ \\
\hline A46G & $\begin{array}{l}\text { F: cattatatcatgaggaaggcgctggaattagtgcacctcaaattg } \\
\text { R: caatttgaggtgcactaattccagcgccttcctcatgatataatg }\end{array}$ & gca-gga & $\mathrm{A} \rightarrow \mathrm{G}$ \\
\hline L131Q & $\begin{array}{l}\text { F: gatatcgcacgcatgattcaacatgagattgatcatcttaatgg } \\
\text { R: ccattaagatgatcaatctcatgttgaatcatgcgtgcgatatc }\end{array}$ & tta-caa & $\mathrm{L} \rightarrow \mathrm{Q}$ \\
\hline M133E & $\begin{array}{l}\text { F: gatatcgcacgcatgattcaacatgagattgatcatcttaatgg } \\
\text { R: ccattaagatgatcaatctcatgttgaatcatgcgtgcgatatc }\end{array}$ & atg-gag & $\mathrm{M} \rightarrow \mathrm{E}$ \\
\hline I47L & $\begin{array}{l}\text { F: catgaggaaggcgctggacttgctgcacctcaaattggagtag } \\
\text { R: ctactccaatttgaggtgcagcaagtccagcgccttcctcatg }\end{array}$ & att-ctt & $\mathrm{I} \rightarrow \mathrm{L}$ \\
\hline S48A & $\begin{array}{l}\text { F: catgaggaaggcgctggacttgctgcacctcaaattggagtag } \\
\text { R: ctactccaatttgaggtgcagcaagtccagcgccttcctcatg }\end{array}$ & agt-gct & $\mathrm{S} \rightarrow \mathrm{A}$ \\
\hline $\mathrm{A} 45 \mathrm{~V}$ & $\begin{array}{l}\text { F: cattatatcatgaggaaggcgttggacttgctgcacctcaaattggag } \\
\text { R: ctccaatttgaggtgcagcaagtccaacgccttccacatgatataatg }\end{array}$ & gct-gtt & $\mathrm{A} \rightarrow \mathrm{V}$ \\
\hline
\end{tabular}

def, encodes a protein containing 183 amino acids (SePDF1). According to amino-acid sequence alignment of PDFs from five species (S. epidermidis, S. aureus, E. coli, Helicobacter pylori and Homo sapiens) (see Supplementary Fig. S1, available with the online version of this paper), SePDF-1 contains three of the most conserved motifs structurally defined as the active sites of the PDF enzymes, and is $80 \%$ identical to the functional PDF in S. aureus (SaPDFB), a representative of the type-II PDF subfamily (Guilloteau et al., 2002; Margolis et al., 2000). This suggested that the def gene product is the functional deformylase in $S$. epidermidis.

The other deformylase homologue gene in S. epidermidis is def-2. The def-2 gene product, SePDF-2, shows only $24.5 \%$ amino acid identity with SePDF-1, and lacks the consensus cysteine and histidine residues that have been shown to be essential for deformylase activity as a metal cofactor binding site (Becker et al., 1998; Meinnel et al., 1997; Rajagopalan et al., 2000). The def-2 gene of S. epidermidis is considered unlikely to encode a protein with deformylase activity.

\section{Biochemical characterization of SePDF-1, the def gene product}

In order to identify the functional peptide deformylase, both of the deformylase-coding genes (def and def-2) were cloned and expressed in E. coli; only SePDF-1 (def coding) was shown to have deformylase activity.

PDFs from most bacteria represent a family of metallohydrolases containing a catalytic $\mathrm{Fe}^{2+}$ ion. Replacing the $\mathrm{Fe}^{2+}$ ion with other divalent transition metals, such as
$\mathrm{Co}^{2+}, \mathrm{Ni}^{2+}$ and $\mathrm{Zn}^{2+}$, resulted in a stable enzyme activity similar to that of PDF with $\mathrm{Fe}^{2+}$ (Groche et al., 1998; Meinnel et al., 1995, 1996; Ragusa et al., 1998; Rajagopalan et al., 1997, 2000). To determine the effects of different metal cations on the catalytic activity of SePDF-1, and to obtain stable and high enzyme activity for subsequent experiments, we prepared $\mathrm{Co}^{2+}, \mathrm{Ni}^{2+}{ }_{-}$or $\mathrm{Zn}^{2+}{ }_{- \text {sub- }}$ stituted SePDF-1 by growing $E$. coli cells in a chemically defined medium supplemented with $100 \mu \mathrm{M} \mathrm{CoCl}_{2}, \mathrm{NiCl}_{2}$ or $\mathrm{ZnCl}_{2}$, respectively. The recombinant SePDF-1 coupled with a C-terminal six-histidine tag was purified to apparent homogeneity by Ni-NTA affinity chromatography (Supplementary Fig. S2). The molecular mass of the recombinant SePDF-1 was confirmed by LC/ESI-MS, and its oligomeric state was analysed by gel filtration. The sizeexclusion chromatography of SePDF-1 showed only one peak between carbonic anhydrase $(29.0 \mathrm{kDa})$ and RNase A $(13.7 \mathrm{kDa})$, as shown in Supplementary Fig. S3. This indicated that the SePDF-1 existed as a monomer in solution state in vitro, whose molecular mass was $21.8 \mathrm{kDa}$.

Compared with Co-SePDF-1, the enzymic activity of $\mathrm{Ni}^{2+}$ or $\mathrm{Zn}^{2+}$-substituted SePDF-1 showed a fourfold decrease (Fig. 1). In contrast, earlier studies found that while the $\mathrm{Zn}^{2+}$-substituted PDFs from E. coli and S. aureus showed reduced activity, the $\mathrm{Co}^{2+}$ - or $\mathrm{Ni}^{2+}$-substituted PDFs retained rather high activity and essential stability (Baldwin et al., 2002; Ragusa et al., 1998; Rajagopalan et al., 2000; Smith et al., 2003). The Michaelis-Menten parameters of Co-SePDF-1 were determined from the slope and intercept values of the linear fit in a Lineweaver-Burk plot. The kinetic parameters $K_{\mathrm{m}}, k_{\text {cat }}$ and the second-order rate constant $k_{\text {cat }} / K_{\mathrm{m}}$ for PDF enzymes from four species are listed in Table 3. The $k_{\mathrm{cat}} / K_{\mathrm{m}}$ value of Co-SePDF-1 was 


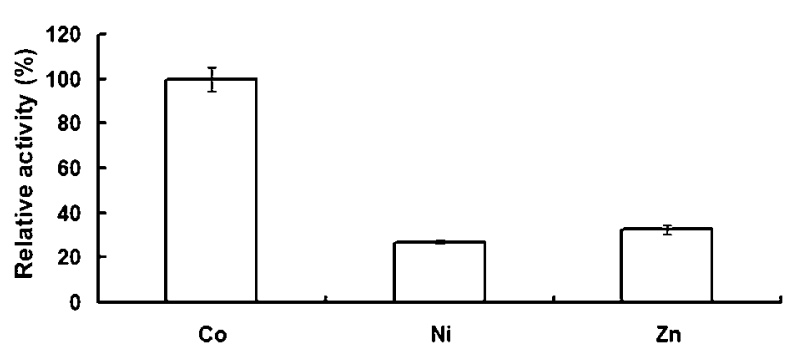

Fig. 1. Enzymic activities of SePDF-1 substituted by different metal cations. SePDF-1 was prepared from cells grown in chemically defined medium supplemented with $100 \mu \mathrm{M} \mathrm{Co}^{2+}$, $\mathrm{Ni}^{2+}$ or $\mathrm{Zn}^{2+}$. The enzymic activities were determined by FDHcoupled assay. The relative enzymic activity of the different enzyme forms $\left(\mathrm{Co}^{2+}, \mathrm{Ni}^{2+}\right.$ and $\left.\mathrm{Zn}^{2+}\right)$ of SePDF-1 was determined by comparing the initial velocities, taking Co-SePDF-1 as $100 \%$.

$6.3 \times 10^{4} \mathrm{M}^{-1} \mathrm{~s}^{-1}$, indicating that the recombinant SePDF1 has high catalytic efficiency. When stored at $4{ }^{\circ} \mathrm{C}$ at a concentration of $>5 \mathrm{mg} \mathrm{ml}^{-1}$ during enzyme purification and kinetic experiments, $\mathrm{Co}^{2+}$-containing SePDF-1 was quite stable and retained similar activity for weeks.

\section{Weak nickel-binding ability of SePDF-1}

In order to study why $\mathrm{Ni}^{2+}$-substituted SePDF-1 was less active, we determined the nickel content in Ni-SePDF-1. Atom absorption spectrum analysis showed that no nickel binding was detectable in SePDF-1 expressed using $\mathrm{Ni}^{2+}$ fortified medium, while cobalt or zinc was normally detected in SePDF-1 expressed using medium containing $\mathrm{Co}^{2+}$ or $\mathrm{Zn}^{2+}$, respectively (Table 4). Considering that the Ni-NTA agarose may bind the $\mathrm{Ni}^{2+}$ ion in the solution in competition with SePDF, additional $\mathrm{Ni}^{2+}$ ions (to a final concentration of $100 \mu \mathrm{M}$ ) were added to the purification buffers. However, SePDF-1 purified using $\mathrm{Ni}^{2+}$-containing buffers still showed no nickel binding. No upregulation of enzyme activity was observed, even when additional $\mathrm{Ni}^{2+}$ was directly added to the enzymic activity assay buffer. These results showed that SePDF-1 had a weak $\mathrm{Ni}^{2+}$ binding ability, although it shared high amino-acid sequence identity $(80 \%)$ with $\mathrm{SaPDFB}$, which has a high enzymic activity in the $\mathrm{Ni}^{2+}$ form (Table 3) (Smith et al., 2003).
SePDF-1 binds more $\mathrm{Zn}^{2+}$ (1.36 mol Zn per mol protein) than $\mathrm{Co}^{2+}(0.87 \mathrm{~mol}$ Co per mol protein), although the activity of $\mathrm{Zn}-\mathrm{SePDF}$ was much lower. The zinc detected in $\mathrm{Co}^{2+}-$ or $\mathrm{Ni}^{2+}$-form SePDF-1 expressed in chemically defined medium may be from the environment.

\section{Crystal structure of SePDF-1}

In order to study the metal ion binding mechanism, and explore the reason for the weak nickel-binding ability of SePDF-1, we crystallized the recombinant protein using the hanging-drop vapour-diffusion method, and analysed the overall structure of SePDF-1. Because of the lack of nickel binding to SePDF-1 and the low activity of Zn-SePDF-1, $\mathrm{Co}^{2+}$ substituted SePDF-1 was used for the crystallography studies.

The crystal structure of SePDF-1 was analysed by molecular replacement using the structure of SaPDFB (PDB code: 1LQW) (Guilloteau et al., 2002) as the search model. Similar to the amino-acid sequences, the crystal structure of SePDF-1 is also similar to that of SaPDFB (Baldwin et al., 2002), with a root-mean-square distance (RMSD) of $0.603 \AA$ superimposing $180 \mathrm{C}_{\alpha}$ atoms out of 183 (Asp80Asn82 were not modelled in SePDFs because of missing electron density). SePDF-1 contains three $\alpha$-helices, four $3_{10}$ helices and eight $\beta$-strands (Fig. 2). The $\mathrm{N}$-terminus of the protein is a cluster of helices, followed by two threestranded anti-parallel $\beta$-sheets wrapping around a central $\alpha$-helix where the catalytic site is located. A three-stranded mixed $\beta$-sheet is positioned at the $\mathrm{C}$-terminus and the tail of its last strand folds back toward the entrance of the substrate-binding pocket. The $\mathrm{Co}^{2+}$ ion is tetrahedrally coordinated by His154 and His158 from the motif HEФDH, Cys111 from the motif EGCФS, and a water molecule held in place by the catalytically active residue Glu155.

\section{Site-directed mutagenesis of SePDF-2}

The def-2 gene product, SePDF-2, was expressed and purified with $\mathrm{Co}^{2+}, \mathrm{Ni}^{2+}$ or $\mathrm{Zn}^{2+}$, and the enzymic activity was evaluated using the same method as for SePDF-1. Distinct from SePDF-1, none of the $\mathrm{Co}^{2+}$, $\mathrm{Ni}^{2+}$ - or $\mathrm{Zn}^{2+}$-substituted SePDF-2 proteins showed peptide deformylase activity.

Table 3. Kinetic parameters of SePDF-1 compared with PDFs from other bacteria

SaPDF, PDF from S. aureus; EcPDF, PDF from E. coli; HpPDF, PDF from H. pylori.

\begin{tabular}{|llccl|}
\hline PDF & $\boldsymbol{K}_{\mathbf{m}}(\mathbf{m M})$ & $\boldsymbol{k}_{\text {cat }}\left(\mathbf{s}^{-\mathbf{1}}\right)$ & $\boldsymbol{k}_{\text {cat }} / \boldsymbol{K}_{\mathbf{m}}\left(\mathbf{M}^{-\mathbf{1}} \mathbf{s}^{-\mathbf{1}}\right)$ & \multicolumn{1}{c|}{ Reference } \\
\hline Co-SePDF-1 & 2.227 & 140 & $6.3 \times 10^{4}$ & Present study \\
Ni-SaPDFB & 2.6 & 152 & $5.8 \times 10^{4}$ & Smith et al. $(2003)$ \\
Ni-EcPDF & 9.1 & 103 & $1.1 \times 10^{4}$ & Smith et al. $(2003)$ \\
Co-HpPDF & 1.7 & 3.4 & $0.2 \times 10^{4}$ & Han et al. $(2004)$ \\
\hline
\end{tabular}


Table 4. Metal contents and enzymic properties of SePDF-1 substituted by different metal cations

\begin{tabular}{|c|c|c|c|c|c|}
\hline \multirow[t]{2}{*}{ Ion-SePDF } & \multicolumn{3}{|c|}{ Metal content ${ }^{\star}$} & \multirow{2}{*}{$\begin{array}{c}K_{\mathrm{m}} \\
(\mathbf{m M})\end{array}$} & \multirow{2}{*}{$\begin{array}{l}k_{\text {cat }} \\
\left(\mathrm{s}^{-1}\right)\end{array}$} \\
\hline & Co & $\mathrm{Ni}$ & $\mathrm{Zn}$ & & \\
\hline Co-SePDF-1 & 0.87 & $<0.01$ & 0.08 & 2.277 & 140 \\
\hline Ni-SePDF-1 & $<0.01$ & $<0.01$ & 0.30 & NA & NA \\
\hline Zn-SePDF-1 & $<0.01$ & $<0.01$ & 0.99 & NA & NA \\
\hline $\begin{array}{l}\text { EDTA-treated } \\
\text { SePDF-1 }\end{array}$ & NS & NS & NS & - & - \\
\hline
\end{tabular}

*The metal contents in the table are given as molar ratios, which were calculated by dividing the metal contents (determined by atomic absorption spectrometry as p.p.m., and then converted to $\mathrm{mol}^{-1}$ ) by the enzyme concentrations $\left(\mathrm{mol} \mathrm{l}^{-1}\right)$. NS, No signal: no significant signal was obtained.

NA, Not analysed, because of low enzymic activity.

Protein sequence analysis showed that SePDF-2 belongs to the type I PDF family, and it has several amino-acid mutations in the three regions which are highly conserved in all PDFs. The cysteine and histidine residues in the metal-binding domain of PDF enzymes are crucial for the peptide deformylase activity, and lack of those conserved residues might result in the inactivity of SePDF-2.

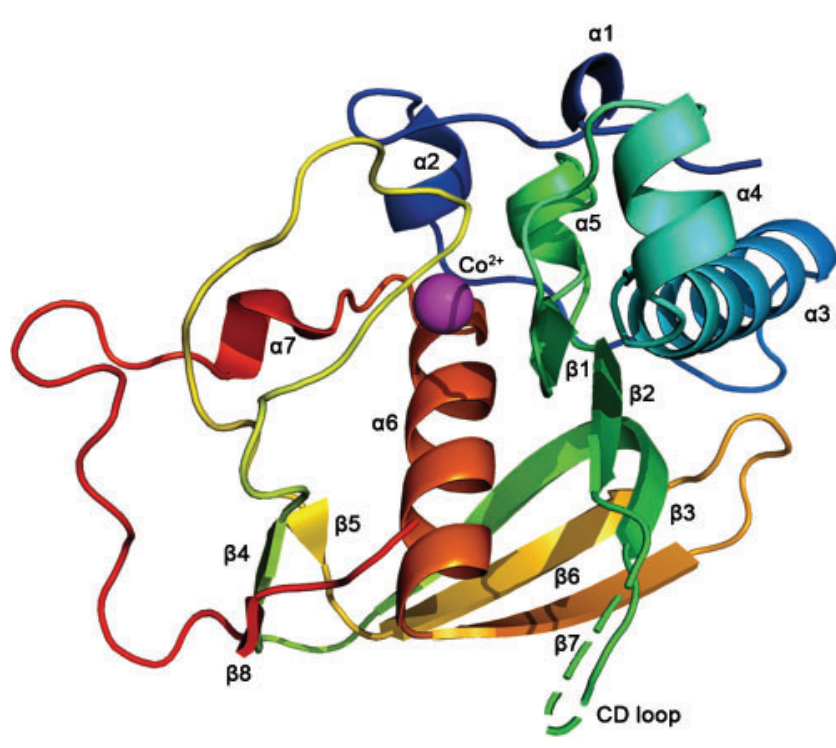

Fig. 2. Cartoon representation of the overall structure of SePDF-1. The whole molecule is coloured in blue to red from its $\mathrm{N}$-terminus to its $\mathrm{C}$-terminus. The secondary structures were assigned by DSSP and are labelled (Kabsch \& Sander, 1983). The cobalt ion is drawn as a magenta sphere, and the dashed green line stands for disordered residues missing in the CD loop. The graphic was generated by Pymol.
Based on the sequence alignment of essential motifs in SePDF-2, SePDF-1 (type II PDF family), BsPDF-1 (type I PDF family, an active PDF in Bacillus subtilis whose def gene products are both proved to be active: Haas et al., 2001), and EcPDF (PDF from E. coli, type I PDF family) (Fig. 3), the essential sites of SePDF-2 were changed by a series of site-directed mutagenesis (A44G, A45V, A46G, I47L, S48A, S90C, I91L, L131Q, M133E) to form a mutant protein with the same active centre as the active BsPDF-1. However, the final mutant with all the sites mutated still showed no peptide deformylase activity in the $\mathrm{Co}^{2+}, \mathrm{Ni}^{2+}$ or $\mathrm{Zn}^{2+}$ forms.

\section{DISCUSSION}

\section{Distinct characteristics of SePDF-1}

Since PDF was considered as a potential target for antimicrobial drug discovery, there have been more and more reports of PDFs from various bacteria. In the present study we have investigated the characteristics of PDF from $S$. epidermidis, and found that the functional PDF in $S$. epidermidis (SePDF-1) has some distinct characteristics compared with that in S. aureus (SaPDFB), although they share $80 \%$ amino-acid sequence identity. The recombinant $\mathrm{Co}^{2+}$-substituted SePDF-1 was highly active towards the peptide substrate formyl-MAS, with a $k_{\text {cat }}$ of $140 \mathrm{~s}^{-1}, K_{\mathrm{m}}$ of $2.227 \mathrm{mM}$, and $k_{\text {cat }} / K_{\mathrm{m}}$ of $6.3 \times 10^{4} \mathrm{M}^{-1} \mathrm{~s}^{-1}$, but the $\mathrm{Ni}^{2+}$-substituted SePDF-1 was less active. Earlier studies have found that $\mathrm{Ni}^{2+}$-substituted PDFs from E. coli and $S$. aureus retained rather high activity (Table 3) (Baldwin et al., 2002; Ragusa et al., 1998; Rajagopalan et al., 2000; Smith et al., 2003), while the enzymic activity of $\mathrm{Ni}^{2+}$ substituted SePDF-1 was much lower, and SePDF-1 showed a weak $\mathrm{Ni}^{2+}$-binding ability (Table 4 ).

To investigate the basis of the weak $\mathrm{Ni}^{2+}$-binding ability of SePDF-1, a structural comparison between SePDF-1 and SaPDFB was performed by the Pymol program, and this

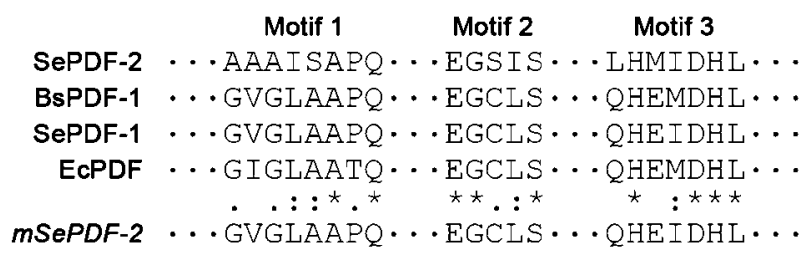

Fig. 3. Sequence alignment of essential motifs in SePDF-2 and PDFs from other species. The most conserved motifs in SePDF-2, SePDF-1, BsPDF1 (PDF1 from B. subtilis, GenBank Accession no. P94462.1), EcPDF (PDF from E. coli, GenBank Accession no. POA6K3.2) were aligned by CLUSTAL W. The conserved residues are marked with an asterisk. Conserved substitutions are represented by (:), and semi-conserved substitutions by (.). The sequence of SePDF2 was mutated to be similar to active BsPDF-1 and SePDF-1, and the mutant was named mSePDF2. 


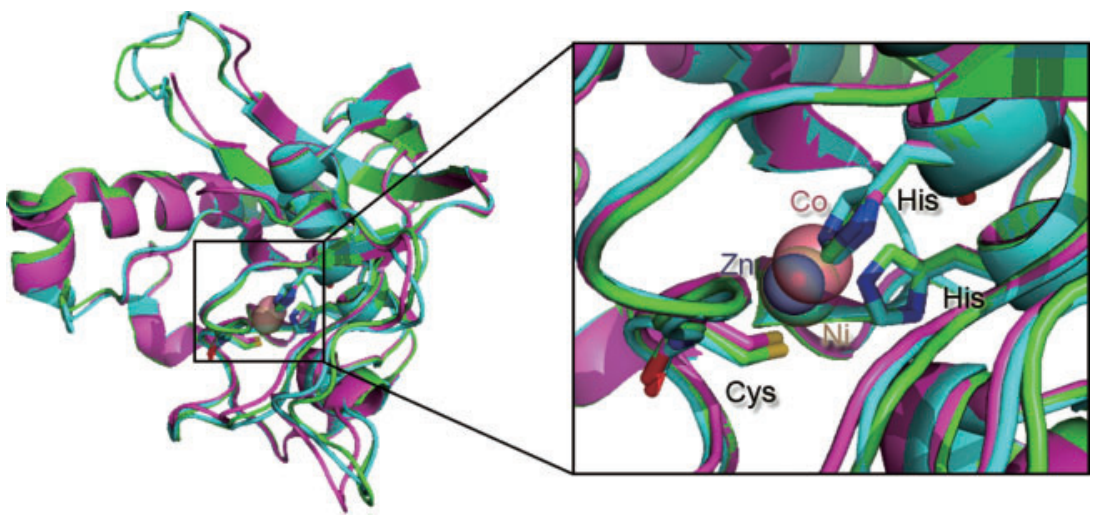

Fig. 4. Schematic representation of superimposed PDF structures. Structures of $\mathrm{Zn}$ SaPDFB (PDB code: 1LQW) (Guilloteau et al., 2002), Ni-SaPDFB (PDB code: 2AI9) (Smith et al., 2003) and Co-SePDF-1 were superimposed by using the Pymol program. Carbons in Zn-SaPDFB, Ni-SaPDFB and Co-SePDF-1 are coloured green, blue and pink, respectively. The cations of $\mathrm{Zn}, \mathrm{Ni}$, and $\mathrm{Co}$ in the structures are represented as brown, blue, and red spheres, respectively.

indicated some structural differences between the two proteins. The first difference was found in the metal-ionbinding domains. Although the metal-binding pattern of SePDF-1 is quite similar to that of SaPDFB, the position of the cobalt ion in SePDF-1 is about $1 \AA$ away from that of zinc and nickel in SaPDFB when their structures are superimposed, which is closer to the catalytic centre of PDF and may be ascribed to subtle displacement of the sidechain of the conserved Cys in the pocket (Fig. 4). Another difference between SePDF-1 and SaPDFB occurs at the CD loop (Pro78-Ser85, in which Asn80-Asn82 was disordered), with an RMSD of $2.11 \AA$. This is in agreement with the intrinsic flexibility of this loop, which is located at the entry point for the substrate. The final difference is in the part of the loop preceding the last $3_{10}$ helix (Asp169Leu174, RMSD $1.49 \AA$ ), probably due to its exposure to the solvent. These structural differences may result in the different nickel-binding pattern between SePDF-1 and SaPDFB, but the detailed reason for the weak $\mathrm{Ni}^{2+}$ binding remains to be further investigated.

\section{Two deformylase homologues}

In the genome of $S$. epidermidis strain RP62A, two deformylase homologues, def and $d e f-2$, were identified. Although both genes were transcribed consistently through all growth phases of $S$. epidermidis (Supplementary Fig. S4), only the def-encoded protein had deformylase activity.

In most Gram-negative bacteria, the gene coding for the functional peptide deformylase is located next to the formyl Met-tRNA transferase-encoding gene $f m t$. However, the def-2 gene of S. epidermidis located next to the fmt ORF encodes a protein without deformylase activity, like $\operatorname{def}-A$ in S. aureus.

Bacillus subtilis is considered to be a model organism for Gram-positive bacteria. Both of the def gene products in B. subtilis have been shown to have peptide deformylase activity (Haas et al., 2001). We were curious about whether def-2 in S. epidermidis might also have encoded an active PDF during an earlier stage of its evolution, and the inactivation of this gene product was due to mutations in the active centre of the protein. Therefore, we mutated def-2 in S. epidermidis to investigate whether the activity of this gene product can be recovered by site-directed mutagenesis.

Protein-sequence analysis showed that SePDF-2 has several single point mutations in the highly conserved activity centres present in all PDF enzymes. Previous studies have demonstrated that the cysteine and histidine residues in the metal-binding domain of PDF enzymes are crucial for the peptide deformylase activity. We therefore assumed that the absence of the key residues in the active centres of SePDF-2 might result in the inactivation of its deformylase activity. The SePDF- 2 was changed by a series of site-directed mutagenesis, and the final mutant had the same active centre as the active BsPDF-1, which also belongs to the type I PDF subfamily. However, none of the SePDF-2 mutants showed deformylase activity. Thus, there must be multiple reasons for the inactivation of SePDF-2. Besides the absence of the crucial residues, the conformational differences between these two proteins may also result in different enzyme characteristics; $\mathrm{Co}^{2+}$, $\mathrm{Ni}^{2+}$ or $\mathrm{Zn}^{2+}$ may not serve as the appropriate metal cofactors for SePDF-2, and the lack of the appropriate metal co-factors (e.g. $\mathrm{Fe}^{2+}$ ) may lead to the inactivation of SePDF-2 as well. In addition, def-2 in S. epidermidis may have some other functions that have not yet been identified.

Taken together, our present work may contribute to a better understanding of the SePDF catalytic mechanism and help to discover potential PDF inhibitors.

\section{ACKNOWLEDGEMENTS}

This work was supported by the Program of Ministry of Science and Technology of China (2009ZX09303-005, 2010DFA32100, 2008ZX10003 -016), the National Natural Science Foundation of China (30800036), the Scientific Technology Development Foundation of Shanghai (08JC1401600, 10410700600), and the High-Tech Research and Development Program of China (2006AA02A253, 2006AA01A124, 2009AA01A137). 


\section{REFERENCES}

Adams, J. M. (1968). On the release of the formyl group from nascent protein. J Mol Biol 33, 571-589.

Apfel, C. M., Locher, H., Evers, S., Takacs, B., Hubschwerlen, C., Pirson, W., Page, M. G. \& Keck, W. (2001). Peptide deformylase as an antibacterial drug target: target validation and resistance development. Antimicrob Agents Chemother 45, 1058-1064.

Baldwin, E. T., Harris, M. S., Yem, A. W., Wolfe, C. L., Vosters, A. F. Curry, K. A., Murray, R. W., Bock, J. H., Marshall, V. P. \& other authors (2002). Crystal structure of type II peptide deformylase from Staphylococcus aureus. J Biol Chem 277, 31163-31171.

Becker, A., Schlichting, I., Kabsch, W., Schultz, S. \& Wagner, A. F. (1998). Structure of peptide deformylase and identification of the substrate binding site. J Biol Chem 273, 11413-11416.

Bracchi-Ricard, V., Nguyen, K. T., Zhou, Y., Rajagopalan, P. T., Chakrabarti, D. \& Pei, D. (2001). Characterization of an eukaryotic peptide deformylase from Plasmodium falciparum. Arch Biochem Biophys 396, 162-170.

Bradshaw, R. A., Brickey, W. W. \& Walker, K. W. (1998). N-terminal processing: the methionine aminopeptidase and $\mathrm{N}$ alpha-acetyl transferase families. Trends Biochem Sci 23, 263-267.

Brünger, A. T., Adams, P. D., Clore, G. M., DeLano, W. L., Gros, P., Grosse-Kunstleve, R. W., Jiang, J. S., Kuszewski, J., Nilges, M. \& other authors (1998). Crystallography \& NMR system: a new software suite for macromolecular structure determination. Acta Crystallogr D Biol Crystallogr 54, 905-921.

Cai, J., Han, C., Hu, T., Zhang, J., Wu, D., Wang, F., Liu, Y., Ding, J., Chen, K. \& other authors (2006). Peptide deformylase is a potential target for anti-Helicobacter pylori drugs: reverse docking, enzymatic assay, and X-ray crystallography validation. Protein Sci 15, 20712081.

Chan, M. K., Gong, W., Rajagopalan, P. T., Hao, B., Tsai, C. M. \& Pei, D. (1997). Crystal structure of the Escherichia coli peptide deformylase. Biochemistry 36, 13904-13909.

Chen, D. Z., Patel, D. V., Hackbarth, C. J., Wang, W., Dreyer, G., Young, D. C., Margolis, P. S., Wu, C., Ni, Z. J. \& other authors (2000). Actinonin, a naturally occurring antibacterial agent, is a potent deformylase inhibitor. Biochemistry 39, 1256-1262.

Dirk, L. M., Williams, M. A. \& Houtz, R. L. (2001). Eukaryotic peptide deformylases. Nuclear-encoded and chloroplast-targeted enzymes in Arabidopsis. Plant Physiol 127, 97-107.

Dong, M. \& Liu, H. (2008). Origins of the different metal preferences of Escherichia coli peptide deformylase and Bacillus thermoproteolyticus thermolysin: a comparative quantum mechanical/molecular mechanical study. J Phys Chem B 112, 10280-10290.

Emsley, P. \& Cowtan, K. (2004). Coot: model-building tools for molecular graphics. Acta Crystallogr D Biol Crystallogr 60, 21262132.

Escobar-Alvarez, S., Goldgur, Y., Yang, G., Ouerfelli, O., Li, Y. \& Scheinberg, D. A. (2009). Structure and activity of human mitochondrial peptide deformylase, a novel cancer target. J Mol Biol 387, 1211-1228.

Evans, P. R. (1993). Data reduction. In Proceedings of CCP4 Study Weekend on Data Collection and Processing, pp. 114-122. Warrington, UK: Daresbury Laboratory.

Fieulaine, S., Juillan-Binard, C., Serero, A., Dardel, F., Giglione, C., Meinnel, T. \& Ferrer, J. L. (2005). The crystal structure of mitochondrial (Type 1A) peptide deformylase provides clear guidelines for the design of inhibitors specific for the bacterial forms. J Biol Chem 280, 42315-42324.
Frottin, F., Martinez, A., Peynot, P., Mitra, S., Holz, R. C., Giglione, C. \& Meinnel, T. (2006). The proteomics of N-terminal methionine cleavage. Mol Cell Proteomics 5, 2336-2349.

Giglione, C., Pierre, M. \& Meinnel, T. (2000a). Peptide deformylase as a target for new generation, broad spectrum antimicrobial agents. $\mathrm{Mol}$ Microbiol 36, 1197-1205.

Giglione, C., Serero, A., Pierre, M., Boisson, B. \& Meinnel, T. (2000b). Identification of eukaryotic peptide deformylases reveals universality of N-terminal protein processing mechanisms. EMBO J 19, 59165929.

Götz, F. (2002). Staphylococcus and biofilms. Mol Microbiol 43, 13671378.

Groche, D., Becker, A., Schlichting, I., Kabsch, W., Schultz, S. \& Wagner, A. F. (1998). Isolation and crystallization of functionally competent Escherichia coli peptide deformylase forms containing either iron or nickel in the active site. Biochem Biophys Res Commun 246, 342-346.

Guilloteau, J. P., Mathieu, M., Giglione, C., Blanc, V., Dupuy, A., Chevrier, M., Gil, P., Famechon, A., Meinnel, T. \& other authors (2002). The crystal structures of four peptide deformylases bound to the antibiotic actinonin reveal two distinct types: a platform for the structure-based design of antibacterial agents. J Mol Biol 320, 951-962.

Haas, M., Beyer, D., Gahlmann, R. \& Freiberg, C. (2001). YkrB is the main peptide deformylase in Bacillus subtilis, a eubacterium containing two functional peptide deformylases. Microbiology 147, 17831791.

Han, C., Wang, Q., Dong, L., Sun, H., Peng, S., Chen, J., Yang, Y., Yue, J., Shen, X. \& other authors (2004). Molecular cloning and characterization of a new peptide deformylase from human pathogenic bacterium Helicobacter pylori. Biochem Biophys Res Commun 319, 1292-1298.

Kabsch, W. \& Sander, C. (1983). Dictionary of protein secondary structure: pattern recognition of hydrogen-bonded and geometrical features. Biopolymers 22, 2577-2637.

Lazennec, C. \& Meinnel, T. (1997). Formate dehydrogenase-coupled spectrophotometric assay of peptide deformylase. Anal Biochem 244, 180-182.

Lee, M. D., She, Y., Soskis, M. J., Borella, C. P., Gardner, J. R., Hayes, P. A., Dy, B. M., Heaney, M. L., Philips, M. R. \& other authors (2004). Human mitochondrial peptide deformylase, a new anticancer target of actinonin-based antibiotics. J Clin Invest 114, 1107-1116.

Leslie, A. G. W. (1992). Recent changes to the MOSFLM package for processing film and image plate data. Joint CCP4+ESF-EAMCB Newsletter on Protein Crystallography 26.

Li, Y., Chen, Z. \& Gong, W. (2002). Enzymatic properties of a new peptide deformylase from pathogenic bacterium Leptospira interrogans. Biochem Biophys Res Commun 295, 884-889.

Margolis, P. S., Hackbarth, C. J., Young, D. C., Wang, W., Chen, D., Yuan, Z., White, R. \& Trias, J. (2000). Peptide deformylase in Staphylococcus aureus: resistance to inhibition is mediated by mutations in the formyltransferase gene. Antimicrob Agents Chemother 44, 1825-1831.

Mazel, D., Pochet, S. \& Marliere, P. (1994). Genetic characterization of polypeptide deformylase, a distinctive enzyme of eubacterial translation. EMBO J 13, 914-923.

Meinnel, T. \& Blanquet, S. (1994). Characterization of the Thermus thermophilus locus encoding peptide deformylase and methionyltRNA(fMet) formyltransferase. J Bacteriol 176, 7387-7390.

Meinnel, T., Mechulam, Y. \& Blanquet, S. (1993). Methionine as translation start signal: a review of the enzymes of the pathway in Escherichia coli. Biochimie 75, 1061-1075. 
Meinnel, T., Lazennec, C. \& Blanquet, S. (1995). Mapping of the active site zinc ligands of peptide deformylase. J Mol Biol 254, 175183.

Meinnel, T., Blanquet, S. \& Dardel, F. (1996). A new subclass of the zinc metalloproteases superfamily revealed by the solution structure of peptide deformylase. J Mol Biol 262, 375-386.

Meinnel, T., Lazennec, C., Villoing, S. \& Blanquet, S. (1997). Structurefunction relationships within the peptide deformylase family. Evidence for a conserved architecture of the active site involving three conserved motifs and a metal ion. J Mol Biol 267, 749-761.

Murshudov, G. N., Vagin, A. A. \& Dodson, E. J. (1997). Refinement of macromolecular structures by the maximum-likelihood method. Acta Crystallogr D Biol Crystallogr 53, 240-255.

Nguyen, K. T., Hu, X., Colton, C., Chakrabarti, R., Zshu, M. X. \& Pei, D. (2003). Characterization of a human peptide deformylase: implications for antibacterial drug design. Biochemistry 42, 99529958.

Nguyen, K. T., Wu, J. C., Boylan, J. A., Gherardini, F. C. \& Pei, D. (2007). Zinc is the metal cofactor of Borrelia burgdorferi peptide deformylase. Arch Biochem Biophys 468, 217-225.

Otto, M. (2008). Staphylococcal biofilms. Curr Top Microbiol Immunol 322, 207-228.

Ragusa, S., Blanquet, S. \& Meinnel, T. (1998). Control of peptide deformylase activity by metal cations. J Mol Biol 280, 515-523.

Rajagopalan, P. T., Datta, A. \& Pei, D. (1997). Purification, characterization, and inhibition of peptide deformylase from Escherichia coli. Biochemistry 36, 13910-13918.

Rajagopalan, P. T., Grimme, S. \& Pei, D. (2000). Characterization of cobalt(II)-substituted peptide deformylase: function of the metal ion and the catalytic residue Glu-133. Biochemistry 39, 779-790.
Robien, M. A., Nguyen, K. T., Kumar, A., Hirsh, I., Turley, S., Pei, D. \& Hol, W. G. (2004). An improved crystal form of Plasmodium falciparum peptide deformylase. Protein Sci 13, 1155-1163.

Rupp, M. E. \& Archer, G. L. (1994). Coagulase-negative staphylococci: pathogens associated with medical progress. Clin Infect Dis 19, 231243.

Serero, A., Giglione, C., Sardini, A., Martinez-Sanz, J. \& Meinnel, T. (2003). An unusual peptide deformylase features in the human mitochondrial N-terminal methionine excision pathway. J Biol Chem 278, 52953-52963.

Sharma, A., Khuller, G. K. \& Sharma, S. (2009). Peptide deformylase - a promising therapeutic target for tuberculosis and antibacterial drug discovery. Expert Opin Ther Targets 13, 753-765.

Smith, K. J., Petit, C. M., Aubart, K., Smyth, M., McManus, E., Jones, J., Fosberry, A., Lewis, C., Lonetto, M. \& other authors (2003). Structural variation and inhibitor binding in polypeptide deformylase from four different bacterial species. Protein Sci 12, 349-360.

Vagin, A. \& Teplyakov, A. (1997). MOLREP: an automated program for molecular replacement. J Appl Crystallogr 30, 1022-1025.

von Eiff, C., Peters, G. \& Heilmann, C. (2002). Pathogenesis of infections due to coagulase-negative staphylococci. Lancet Infect Dis 2, 677-685.

Wang, Q., Zhang, D., Wang, J., Cai, Z. \& Xu, W. (2006). Docking studies of Nickel-Peptide deformylase (PDF) inhibitors: exploring the new binding pockets. Biophys Chem 122, 43-49.

Zhou, Z., Song, X. \& Gong, W. (2005). Novel conformational states of peptide deformylase from pathogenic bacterium Leptospira interrogans: implications for population shift. J Biol Chem 280, 4239142396.

Edited by: V. Eijsink 